\title{
LegalAve: A Centralized Website for Family Law Resources in Alberta
}

\author{
Katy Moore \\ Information Specialist, Alberta Legal Information Society \\ 780.756.9823 \\ katymoore@albertalegalinformationsociety.ca
}

The Alberta Legal Information Society (ALIS) recently launched a new information portal for Albertans dealing with family law issues. LegalAve.ca is a free website that provides in-depth information about family law, linking users to existing legal resources from different organizations in the province and across Canada. The website is intended to serve as a starting point for legal research for the general public and professional service providers alike.

The ALIS team consulted with legal and social service providers, librarians, and lawyers across Alberta about what they wanted to see in an online legal information resource. The team incorporated the feedback into a variety of website features that make using LegalAve intuitive and easy to navigate.

- The "Guided Pathway" tool asks users a series of questions about their particular situation to direct them to the relevant LegalAve web pages.

- There are individual pages that focus on a specific family law topic. Each contains in-depth information on the laws and processes for that topic (both in and out of court), common questions and myths, and links to external resources.

- The "For Service Providers" section of LegalAve is designed for librarians and other professional service providers who help clients find accurate and reliable information. The advanced search functions, filtering options, and "shopping cart" features make it easy for service providers to search, gather, and send/share quality information with clients and other parties.

- LegalAve provides the connections between legal information, community services, legal processes, and the basics of legal research (including referrals to law libraries for further assistance).

To date, LegalAve contains links to over 3,500 resources, including booklets, web pages, tip sheets, legislation, forms, reports, and court cases.

The website currently addresses family law in Alberta. "Family law" is broadly defined and divided into five categories:

1. Starting new family relationships. This includes creating new family or "familylike" relationships, such as marriage and other romantic relationships, certain 
non-romantic relationships, becoming a parent, and related issues (such as fostering, kinship care, and guardianship).

2. Issues in ongoing family relationships. This includes legal issues that people may face as a family (such as children's rights, child welfare, aging parents, preparing for illness and death, taking over a family member's decision-making power, and helping family members out financially).

3. Breakdown in family relationships. This includes ending romantic and nonromantic family relationships, as well as all of the issues that can result (such as the care of children, child support, spousal support, and division of property).

4. Family violence. This includes information about how to identify family violence, how to prepare to leave a violent family situation, and how the law can help keep your family safe.

5. Solving family law problems. This includes information about navigating the legal system, alternatives to court, doing your own legal research, and where to get help with legal issues.

There are plans to expand to other areas of law in the future.

The LegalAve project was initiated by public and law librarians to help deal with a gap in legal information delivery and access to justice in Alberta. Recognizing that everevolving technologies continue to impact libraries and how people access information, it was time to develop a new style of online portal for curated legal resources. A notable strength of LegalAve is that the links to external legal resources are provided within the background context of each topic so that users can easily understand the relevance of the materials.

The Alberta Legal Information Society is committed to facilitating access to justice through collaborative approaches by offering LegalAve as a tool to connect people, communities, and services to address family law matters in Alberta. The Alberta Legal Information Society and the LegalAve project are funded by the Alberta Law Foundation. 